\title{
The Effect of Music Therapy on Problem-Solving Skills
}

\author{
Zeinab Sirous Jahedi \\ Student of Ph.D, Department of Public Psychology, College of Human Science \\ Bushehr Branch, Islamic Azad University, Bushehr, Iran
}

\begin{abstract}
Nasser Amini Khoi
Assistant Professor, Department of Public Psychology, College of Human Science

Bushehr Branch, Islamic Azad University, Bushehr, Iran
\end{abstract}

Doi:10.5296/ jsr.v6i2.8979

URL: http://dx.doi.org/10.5296/ jsr.v6i2.8979

\begin{abstract}
The aim of the present research was study of the impact of music therapy on problem-solving skills of 4 to 6 years old children in Tehran. This research was a quasi-experimental study with pretest-posttest control group. The statistical population was all 4 to 6 years old children in region 2 of Tehran. Using the random sampling method, the study sample was chosen in two experiment (15 individuals) and control (15 individuals) groups. The experiment group received 12 sessions of music therapy and the control group was waiting for treatment meanwhile. To evaluate the problem-solving skill in children, the three subscales of Wechsler's Preschool and Primary Scale of Intelligence (WPPSI) were used, including: mazes, cubes and arithmetic. Analysis of data obtained from the questionnaires was conducted in two parts of descriptive and inferential. The data analysis indicated the significant increase of problem-solving average score of the experiment group compared to the control group.
\end{abstract}

Keywords: Music therapy, problem-solving skills, the Wechsler Intelligence 


\section{Introduction}

Throughout history, art has been a means of adaptability, flexibility, creativity, love, friendship, and human peace. Among the arts due to an energizing, moving, high abstraction possibility, and intrinsic abstraction nature, music has been so effective and has incredibly attracted humans. There are many different types of music with different types of impacts on mind and body, and due to these impacts, music can be used as treatment activities in fields of counseling and (Zadeh Mohammadi, 2010). Music Therapy Association of America (2009; cited in Kianpour, 2011) has defined the music therapy as Therapeutic use of music to achieve goals tailored to the mental, social, emotional and spiritual needs of the sick. Like other creative therapies, music therapy runs in different methods and music therapists may stimulate or calm their patients by music (Simpsons, 2009).

Generally, there are two types of music therapy according to the patient's need, which are the active and passive methods. Active music therapy involves singing, playing or composing and passive music therapy includes listening to music (Canyon, 2007). Various studies indicate the impact of active music therapy as an impressive tool of improving compatible behavior and decreasing children's negative emotions. At different behavioral and motivational levels, sensorimotor musical activities establish a safe, moving, and pleasant space, and make it possible to make therapeutic relationships, personal and group experiences, and also to increase children's adaptive functioning. Listening, reading, playing and different rhythmic and melodic mental manipulation would create various mental opportunities for active and successful participation of children and their acceptance in group (Peters, 2006).

In line with this topic, one of the public educating goals of every country, including ours, is to raise curious and questioning children that are capable of dealing with their own affairs (Baraie, Mahraam and Kaashki, 2013). In recent decades, the teaching-learning process has changed and there is no longer believed that children minds are as empty containers waiting to be filled with knowledge (Rangdoost, 2011).

Generally, the highest goal of educational system at all levels is creation of problem-solving skills and creativity in learners, because problem-solving and creativity are of the main processes of thinking (Seif, 2010). Problem-solving is cognitive process that interacts with a lot of other cognitive processes including abstraction, research, learning, inference and analysis. Development of problem-solving skills for mental growth of children is a basic skill creating preparations leading to academic success (Cunningham, J. B. and MacGregor, 2008).

As a major subject of cognitive sciences, Problem-solving is one of the basic dimensions of personal life. Individual's ability to solve problems determines the growth of a healthy personality and establishment of positive social interactions (Larson and Busse, 2006). Problem-solving is also a cognitive-behavioral process that the individual uses to identify and discover adaptive solutions in order to face the daily life issues (Shokuhi Yekta, Davaie, Zamani, Pourkarimi, and Sharifi, 2013). Development of problem-solving skills in children is a subject that has been considered a lot by educational trainers and psychologists in recent decades (Zimmerman and Schunk, 2014), because this skill emerges 
in lives of children, while many of the basic tasks of the adult are issues for children to learn (Ziegler and Lybaly, 2007).

Therefore, training in early childhood is considered in two aspects of sensitivity and ease of children's affectivity from educational environments and their persistence and deep learning in this period. In other words, primary learning provides a good background for children to achieve further experiences, and what is taught in early years of life and preschool is more sustainable (Berger and Riojas-Cortez, 2004).

In recent decades, music is used as an effective strategy to enhance communicative, cognitive and emotional abilities of children. Many experts and trainers believe that the musical responses of children are the most spontaneous and natural reactions and play an important role in different fields of learning (Burnard, 2000).

In this research, we seek for the effect of music. Music is an art with performance area of combination of tones and sound effects in order to create emotional expression (Fitch, 2006). Today, music and its neuropsychological effects have attracted attention of many researchers around the world. In psychology filed, music is considered as a common language with its certain areas in brain, and like a language, its comprehension requires education (Evans, 2007). In a research, Bunt (2006) indicated that learning music has a direct relationship with increase of children's IQ. Musical trainings have also important effects on memory and selective spatial attention in children; on the other hand, it's proven that music has a positive effect on children's ability in problem-solving. In addition to what is mentioned, music causes the improvement of individuals' performance at lessons.

Various studies indicate the impact of music therapy methods as an effective tool for improvement of children's behavior. At different behavioral and motivational levels, sensorimotor musical activities establish a safe, moving, and pleasant space, and make it possible to make therapeutic relationships, personal and group experiences, and also to increase children's adaptive functioning (Zadeh Mohammadi, Malek Khosravi, Sadro Sadat and Bireshk, 2006).

Review of the music studies indicate that music associates with the development of problem-solving skills in many cases, namely, dealing with thoughts and imaginations by establishing a link between abstraction and building patterns, while their intended relationship patterns are nonverbal. Therefore, this study sought to answer this question: is teaching music effective on growth of problem-solving skills of 4 to 6 children?

Finally, it can be said that the possible benefits of this research include the following cases:

- Music stimulates the physical activity;

- Music creates a sense of beauty and aesthetic in individuals;

- Music causes emotional discharge;

- Music is a form of communication;

- Music can form a structure into group activities. 


\section{Al Macrothink}

Therefore in this research, we intend to study the effectiveness of music therapy on problem-solving of 4 to 6 years old children in Tehran city.

\section{Methodology}

In this research, the quasi-experimental study was used with pretest-posttest control group. In this study, the experiment group was affected by the independent variable and remained on the waiting list for the control group. To evaluate the changes of the independent variable, at first, a pretest was conducted on the two groups, then the experiment group was subjected to the independent variable (music therapy), and the test was performed on both groups with a specified interval, and by comparison of the two group results, the research hypotheses were judged. The research design diagram is presented in the table below.

Table 1: Diagram of project

\begin{tabular}{|l|l|l|l|l|}
\hline groups & $\begin{array}{l}\text { Random } \\
\text { assignment }\end{array}$ & pre-test & $\begin{array}{l}\text { independent } \\
\text { variable }\end{array}$ & Post-test \\
\hline examination group & RE & T1 & X & T2 \\
\hline control group & RC & T1 & - & T2 \\
\hline
\end{tabular}

The statistical population of the present research consisted of all 4 to 6 Year children from Preschool and kindergarten in region 2 of Tehran in 2015. In this study, the simple random sampling method was used. Initially through a public call (in preschools and kindergartens of region 2 of Tehran), all the parents of 4 to 6 year children were invited to visit the centers for music therapy on Children and the number of 120 people were willing to do research, then after visiting the willing parents, they were given the objectives and details of the information. Finally, 80 individuals declared their final agreement. Through the 80 individuals, number of 30 children was randomly chosen for the research sample, and the children were randomly divided into the two groups of experiment and control (15 individuals). All of these children and their parents answered the problem-solving skills questions.

The data collection tool in this research was a 15 item questionnaire that is fully described further. It should be noted that the questions of the questionnaire were set to the 5-point Likert scale. This was done in such a way that the closest answers to the response rates were higher and vice versa.

Problem-solving skills questionnaire: it's composed of 15 questions with 3 subscales of arithmetic, mazes and cubes (each 5 questions) adopted from the Wechsler standard intelligence test. There further clarification of the questionnaire and the Wechsler Intelligence Scale in the following:

The subscale scores of this research are addable together and its score is fit into the interval 
scale (Razavie and Shahim, 2000). The criterion for selection of this test method is a contemporary combination of different cognitive affaires that each individual may be faced with throughout their lives. In the arithmetic subscale, children face with the basic problems such as the concepts of mathematical smaller, larger, equal, count, and add and subtract operation. These problems require the recall of information from the long-term memory, while solving problems of mazes and cubes subscales doesn't need the recall of previous information and the information of the very questions is enough. The cubes subscales make the spatial intelligence of children active. Using the test-retest method, the reliability of the 3 subscales of arithmetic, maze and cube was respectively calculated $0.51,0.87$, and 0.62 , and their internal validity of practical intelligence was respectively $0.60,0.72$, and 0.83 (Razavieh and Shahim, 2000).

\section{Revised Wechsler Intelligence Scale for pre-school Children}

Wechsler intelligence scale was developed to evaluate the intelligence for pre-school 5 to 7 year children. The revised form of Wechsler (WPPSI_R) has made it possible to evaluate the intelligence of children from 3 to 7 years old. Almost half of the Wechsler articles are taken from the Wechsler test (WISC). The revised Wechsler test has also a number of subscales grouped into two scales of verbal and practical intelligence. Some of the features used in design of the revised Wechsler test, make it easier to be conducted on the young children. One of these features is the emphasis on the simple verbal instructions and responses, and the other one is the attractive colorful test materials for the young children. There are three different subtests of the revised Wechsler test including: houses of animals, geometric design and sentences (storage test). Thus, the revised Wechsler test for pre-school children has also a verbal and a practical scale. The verbal scale has 5 subtests plus a storage subtest (making sentences) and the practical scale has also 5 subtests. The verbal scale includes subtests of general information, vocabulary, Migna.ir, calculation similarities, comprehension, and sentences, and the practical scale also includes subtests of houses of animals, assembling Pictures, mazes, cubes designing, and geometry designs. The sentences subtest is a memory test that is used instead of digit span. The tester reads every sentence clearly and the subject should immediately tell it from memory. This subtest can be used instead of one of the 5 verbal subtests evaluating the short-term memory. The house of animals subtest is like digit symbols test on adult scale with encryption subtest on a scale of children. In this test, images of some animals such as dogs, birds, fish and cats are drawn on a plaque. There are also different cylinders with different colors and the subject should put the cylinders beneath the images with the same colors. These cylinders are regarded as animal burrows. In the geometric designs test, the subjects are asked to draw on the given designs by black pencil.

The results due to review of validity and reliability indicated that the calculated Cronbach's alpha coefficient for the problem-solving skills structure is greater than 0.7 (0.84). Therefore, it can be concluded that the questionnaire has acceptable research reliability. Similarly, to assess the validity of the questionnaire, it was confirmed by related experts.

Finally, the covariance analysis was used in order to test the hypotheses in the present 
research.

\section{Findings}

In this section, the variable of problem-solving skills of descriptive statistics such as average, mode, index, standard deviation, and variance are inserted from EXCEL 2013 and the results are shown in tables and diagrams. Before concluding any analysis, it should be noted that all of the questions got consistent with each other, and then the data inserted into the software in order to avoid facing with errors.

According to the table below indicating the average and standard variation of the children's problem-solving variable in two groups of experiment and control before and after concluding the test, it should be said that the average scores of problem-solving skills for experiment and control group individuals were respectively 54.69 and 53.49 in the pre-test level, which shows the relative superiority of the control group individuals in problem-solving skills, But as indicated in the table, this value caused the superiority of the test group individuals over the control group individuals after the test, because the average score of problem-solving skills for the experiment group individuals was 57.99 after the music therapy, which was higher than 53.79 in control group individuals.

Table 2- Descriptive data of problem-solving scores in pre-test of the two groups

\begin{tabular}{|l|l|l|l|l|}
\hline \multirow{2}{*}{ variable } & \multicolumn{2}{|l|}{ control group } & \multicolumn{2}{l|}{ test group } \\
\cline { 2 - 5 } & average & Standard variation & average & Standard variation \\
\hline $\begin{array}{l}\text { Problem-solving } \\
\text { skills }\end{array}$ & 54.69 & 10.4 & 53.49 & 9.65 \\
\hline
\end{tabular}

Table 3- Descriptive data of problem-solving scores in post-test of the two groups

\begin{tabular}{|l|l|l|l|l|}
\hline \multirow{2}{*}{ variable } & \multicolumn{2}{|l|}{ The control group } & \multicolumn{2}{l|}{ The test group } \\
\hline & average & Standard variation & average & Standard variation \\
\hline Problem- solving skills & 53.79 & 10.5 & 57.99 & 11.55 \\
\hline
\end{tabular}

The Shapiro-Wilk test

The table below indicates the results of studying the Shapiro test on problem-solving skills variable:

Table 4- study of normalization of the data distribution using the Shapiro test on the skills of 
solving problem.

\begin{tabular}{|l|l|l|l|l|}
\hline \multirow{2}{*}{ variable } & \multicolumn{3}{|l|}{ Shapiro-Wilk test } \\
\cline { 3 - 5 } & & Value & Degree of freedom & Significance level \\
\hline \multirow{2}{*}{ Problem-solving skills } & control & 0.874 & 15 & 0.074 \\
\hline & test & 0.896 & 15 & 0.38 \\
\hline
\end{tabular}

According to the results of the Shapiro test, the calculated values for the tests aren't significant at level of 0.05 for the groups, therefore the condition of equality of inter-group variances is established and the data distribution is normal.

In addition to review of the data normality, the covariance homogeneity of the inter-group scores of subjects are studied, and the results are presented in the table below:

Table 5- results of the Levine test for review of covariance homogeneity of the inter-group scores of subjects $(n=30)$

\begin{tabular}{|l|l|l|l|l|}
\hline variable & F & df1 & df2 & Significance level \\
\hline Problem-solving skills & 1.587 & 1 & 28 & .278 \\
\hline
\end{tabular}

According to the table above using the Levine test, the covariance homogeneity of pre-test scores is studied. Considering that the Levine F value was not significant at level of $\alpha=0.05$, therefore, the homogeneity of data covariance and the regression slope are established.

\section{Hypotheses testing}

Music therapy impacts on increase of children's problem-solving skills in ages of 4 to 6 .

In the table below, a summary of the results of the covariance analysis is presented:

Table 6- summary of the covariance analysis results (MANCOA) for the first hypothesis $(\mathrm{N}=30)$ 


\begin{tabular}{|l|l|l|l|l|l|l|l|l|}
\hline $\begin{array}{l}\text { Index } \\
\text { Source }\end{array}$ & of changes & $\begin{array}{l}\text { Total } \\
\text { squares }\end{array}$ & $\begin{array}{l}\text { Degree } \\
\text { of } \\
\text { freedom }\end{array}$ & $\begin{array}{l}\text { Average } \\
\text { of } \\
\text { squares }\end{array}$ & F & $\begin{array}{l}\text { Significance } \\
\text { level }\end{array}$ & $\begin{array}{l}\text { Etta } \\
\text { coefficients }\end{array}$ & $\begin{array}{l}\text { Test } \\
\text { power }\end{array}$ \\
\hline $\begin{array}{l}\text { group } \\
\text { effect }\end{array}$ & $\begin{array}{l}\text { Problem-solving } \\
\text { skills }\end{array}$ & 435.578 & 1 and 28 & 3.798 & 15.038 & .001 & .391 & .968 \\
\hline
\end{tabular}

According to the table above, the $\mathrm{F}=15.038$ is significant in problem-solving skills variable at $\alpha=0.01$ level. Therefore, it can be concluded that music Therapy impacts on increase of problem-solving skills of 4 to 6 years children. The Etta value indicates the effect of music therapy on increase of problem-solving skills of 4 to 6 years children equal to 0.39 percent. Therefore, the first hypothesis of the research is confirmed at $99 \%$ confidence level. The comparison between the averages of control and experiment groups in descriptive statistics indicated that the average of experiment group is increased in the post-test level. Therefore, music Therapy has a 39 percent improvement of problem-solving skills in the experiment group children, while there is no noticeable change in problem-solving skills of the control group.

\section{Conclusions}

In this section, the results of the study are interpreted based on the collected data through the statistical tests.

As the findings indicated, music therapy is effective on problem-solving skills of 4 to 6 years old children. Our final review on the corrected scores of Wechsler test indicated that music has a significant and positive impact on children's problem-solving skills. Social values of learning music are based on theories that some of their parts refer to the meta- musical effects of music education in childhood. This theory dates back to more than a century in America, and several scientific studies have been conducted in recent years (Bill Hartz et al. 2000) and the most common results of these researches have been the effectiveness of learning music on cognitive growth, abstract thinking, and problem-solving skills generally (cited in Rauscher and Zupan, 2000). Some studies have also have proven that there is a relationship between musical abilities and Spatial-temporal reasoning abilities (problem-solving).

The results of Evans et al. (1999) and the similar studies, reviewing the difference between the two brain hemisphere performances in music education, indicated that the left hemisphere of brain works specifically (Fazaie, 2014). This finding, along with the fact that the left hemisphere has its most performance in problem-solving and analysis-oriented mental processes which are considered as results of reasoning (Gilman and Newman, 1996), leads us to this point that the improvement and facilitation of performance in the left hemisphere (through early education of music) increases the abilities due to this part of brain, including the mind's required components for reasoning (Chan et al., 2000). Therefore, learning music has a relationship with an increase in IQ (Stenberg, 2004). Some effects of music education 
on children are known as memory, selective attention, spatial abilities, mathematics and reading. On the other hand, it is proven that music has positive impacts on children's ability in solving social issues (Olafsdottir et al., 1999; cited in Fazaie, 2014). In addition to these, music also improves academic performance of individuals (Gardiner et al., 1996).

Therefore, the causes of music education impact on children's problem-solving skills are the activities and games that increase the children's ability in comprehension indirectly. For example, the classification of the musical instruments based on the type (melodic and non-melodic), material (wooden and metallic), sound type (treble, bass and medium), size (big and small), and the classification of musical notes in terms of time value (short and long) can be noted.

there were also exercises in practical activities in which the children would learn the concept of aligning and sequence (for example, to play the instruments, they must first learn how to play the pick on the blades of instrument which are arranged from the small to large based on the musical notes). Therefore, the constructive impact of art and artistic activities is very much that Steiner Waldorf believes that the educational system is nothing but art (Miller, 2008).

In line with the results of the past researches, this result in this research seems to be due to the following reasons.

The highest goal of educational system at all levels is creation of problem-solving skills and creativity in learners, because problem-solving and creativity are of the main processes of thinking (Seif, 2010). Development of problem-solving skills for mental growth of children is a required basic proficiency. Problem-solving creates preparations leading to academic success (Kankar and Sharma, 2012). Lang et al. (2004) state that problem-solving requires purposeful and special strategies that the individual defines the issues by them, decides to take the solution, performs the problem-solving strategies, and monitors them. Akinsola (2008) defines the problem-solving as involvement in a task with no specified solution

Therefore, training in early childhood is considered in two aspects of sensitivity and ease of children's affectivity from educational environments and their persistence and deep learning in this period. In other words, primary learning provides a good background for children to achieve further experiences, and what is taught in early years of life and preschool is more sustainable.

One of the important fields including both educational and medical dimensions is art. Throughout history, art has been a means of adaptability, flexibility, creativity, love, friendship and peace. Among arts due to energizing, mobility, possibility of high abstraction, and intrinsic attractions, music is very effective and has incredibly attracted humans (Zadeh Mohammadi, 2009). In recent decades, music is used as an effective strategy to enhance communicative, cognitive and emotional abilities of children. Many experts and trainers believe that the musical responses of children are the most spontaneous and natural reactions and play an important role in different fields of learning.

Therefore, the positive effect of music and its applications on human brain performance isn't 
a new affair. Especially about the specific types of classic music, such impacts have been utilized, specifically in problem solving skills which is being reviewed in the past decades. There are only a few similar studies reviewing this effect directly. This study could prove the positive impact of music on attention and practical memory performance in individuals. In this research in several aspects, it's proven that the effects of listening to music appear shortly, which can be considered as accepted standard criteria, and also Wechsler's problem-solving skills and memory improvement can be shortly observed. Therefore, music can be used in many clinical and non-clinical stressful situations as well. It is hoped that a better understanding of music impacts opens a way for practical applications of music in various fields.

In line with this research, it's proposed to put the collaborative learning the center of our educational activities and never stop supporting it (such as music therapy).

Lack of suitable location was of limitations of this research. Music therapy interventions need space and physical facilities so the subjects will be able to operate with complete discretion, but there was no such place in the centers and there was also no possibility to take the subjects to other places. Lack of possibility to choose the right time of sessions by the researchers was another limitation of the research, such as administrative constraints and interference of children classes. It is also suggested to the further researchers to keep up with the results of this research in order to reveal the effect of the interference within the two months period.

\section{References}

1. Baraie, A; Mahraam, B. and Kurashiki, H. (2013). Importance of problem-solving in training elementary science textbooks. Research in the curriculum, the tenth year of the second period, 12 (39), pp. 1-10.

2. Peters, Jacqueline Schmidt. (2006). Introduction to Music Therapy. Translated by Ali Mohammadi. Tehran: Asraar Danesh Press, second edition.

3. Razavieh, A \& Shahim, S. (2000). Wechsler Intelligence Scale for pre-school adaptation and standardization in Shiraz.Humanities and Social Sciences, 10 (26), Pp: 49-74.

4. Zadeh Mohammadi, A. (2009). Music therapy applications. Tehran: Asraar of knowledge publications.

5. Zadeh Mohammadi, A., Malek Khosravi, Ghaffar, S., SJ and Birashk, B., (2006). The effect of music therapy in reducing behavioral and emotional disorders of orphans. Journal of Psychology, Y.10, N. 2

6. Ziegler, Robert and Lybaly, Martavagnr. (2007). Children's thinking "cognitive developmental psychology. Translation: Kamal Kharrazi. Tehran: Jahaad Daneshgahi Publications. 


\section{Macrothink}

Journal of Sociological Research

ISSN 1948-5468

2015, Vol. 6, No. 2

7. Seif A. (2010). Modern educational psychology: psychology of learning and teaching. Tehran: Doran publications.

8. Shokuhi Yekta, M, Davaie, M., Zamani, N., Pourkarimi, J. and Sharifi, A. (2013). The impact of the program "I can fix the problem" on improvement of problem-solving skills and social skills of preschool and first grade. Periodical of cognitive sciences news, Vol. 15, No. 3, pp. 73-82.

9. Gilman, SA. And Newman, S. (1996). Principles of clinical neuroanatomy and neurophysiology of Munter and Gatz (translated by S.M. Hasani Barzi. and. S.M. Hasani Barzi) first edition, Tehran: Forough Andishe publications.

10. Miller, J. P. (2008). Curriculum theories. Translation: Mehrmohammadi, M. Tehran: SAMT publications, (date of original publication, 1983).

11. Akinsola. M.K (2008). Relationship of some psychological variables in predicting problem solving ability of in-service mathematics teachers. The Montana mathematics enthusiast, 5(1):79-100

12. Berger, E. H., \& Riojas-Cortez, M. (2004). Parents as partners in education: Families and schools working together. Merrill.

13. Bilhartz, T.D., Bruhn, R.A., \& Olson, J.E. (2000). The effect of early music training on child cognitive development. Journal of Applied Developmental Psychology, 20, 615-636

14. Bunt, L. (2006). Music therapy for children (pp. 273-288). Oxford University Press.

15. Burnard, P. (2000). How children ascribe meaning to improvisation and composition: rethinking pedagogy in music education. Music education research, 2(1), 7-23.

16. Chan, A.S., Cheung, M.C., Ho, Y.C., \& He, W.J. (2000). Localized brain activation by selective tasks improves specific cognitive functions in humans. Neuroscience Letters, 283, 162- 164 .

17. Cunningham, J. B., \& MacGregor, J. N. (2008). Training insightful problem solving: Effects of realistic and puzzle-like contexts. Creativity Research Journal, 20(3), 291-296.

18. Evans, H. M. (2007). Medicine and music: three relations considered. Journal of Medical Humanities, 28(3), 135-148.

19. Fitch, W. T. (2006). The biology and evolution of music: A comparative perspective. Cognition, 100(1), 173-215.

20. Gardiner MF, Fox A, Knowles F, Jeffrey D. Learning improved by arts training. Nature 1996; 381: 284.

21. Kenyon, T. (2007). Effects of music therapy on surgical and cancer patients. Breast care, 2, 217-220 


\section{I Macrothink}

Journal of Sociological Research

ISSN 1948-5468

2015, Vol. 6, No. 2

22. Kianpour, O. (2011). Study on Effectiveness and Comparison of Music Therapy on the Basis of Iranian Music and Cognitive Therapy on Anger Control in Adolescent Boys. (Master's Thesis, Allameh Tabatabaie University). (Persian)

23. Lang, C. R., Mastropieri, M. A., Scruggs, T. E., \& Porter, A. (2004). The effect of self-instructional strategies on problem solving in algebra for students with special needs. Advances in Learning and Behavioral Disabilities, 17, 29-54.

24. Larson, J., \& Busse, R. T. (2006). A problem-solving approach to school violence prevention. Handbook of school violence and school safety: From research to practice, 73-88.

25. Ranjdoost, S (2011). Studying the Utilization of Constructivism Theory and Problem solving Method in the Development of Guidance School Science Text Books. Research in Curriculum Planning, 8(30): 11-27

26. Rauscher, F.H., \& Zupan, M.A. (2000). Classroom keyboard instruction improves kindergarten children's spatial temporal performance: A field experiment. Early Childhood Research Quarterly, 15, 215-228.

27. Schulenburg EG. Music lessons enhance IQ. Psychol Sci 2004; 15: 511-14. Ulfarsdottir LO, Erwin PG. The influence of music on social cognitive skills. The arts in psychotherapy 1999; 26: 81-84.

28. Simpson A. (2009). Music therapy for depression home page on the internet Available from: Suite 101. Com

29. Zadeh Mohammadi, A. (2010).Usages of music therapy. Tehran: Asrare danesh. (Persian).

30. Zimmerman, B. J., \& Schunk, D. H. (Eds.). (2014). Educational Psychology: A Century of Contributions: A Project of Division 15 (educational Psychology) of the American Psychological Society. Routledge. 